\title{
Boundary Assignment: A Cognitive Motivation for Lexicalization
}

\author{
Liu Chendan \\ Foreign Languages School, Henan University, Kaifeng, China
}

\section{Email address:}

liucd567@163.com

\section{To cite this article:}

Liu Chendan. Boundary Assignment: A Cognitive Motivation for Lexicalization. International Journal of Language and Linguistics. Vol. 6, No. 4, 2018, pp. 110-117. doi: 10.11648/j.ij11.20180604.12

Received: June 26, 2018; Accepted: July 7, 2018; Published: August 4, 2018

\begin{abstract}
Lexicalization is a process of structural innovation in language change, which is motivated by a human cognitive ability of structural boundary assignment in the construction of linguistic structures. In this process, the first innovative form may be a result of a language user's intentional violation of a structural organization rule for a certain communicative purpose. The receiver, trying to correctly understand what the producer means, will have to make cognitive efforts to establish a structural gestalt by way of assigning structural boundaries. If the receiver's boundary assignment comes to an agreement with the producer's and accords with Gestalt Laws in human cognition, the innovative form will be accepted and spread in the language community and then finally entrench itself as new grammatical convention. That is the general process of lexicalization. The boundary assigning tendency manifested in the process of linguistic structure construal is a cognitive ability dominated by Gestalt Laws in human cognition of the world and world relations, which is actually a driving force for linguistic structural organization, and therefore an important motivation for lexicalization.
\end{abstract}

Keywords: Lexicalization, Gestalt Establishment, Boundary Assignment, Cognitive Motivation

\section{Introduction}

Lexicalization and grammaticalization are two important aspects in language evolution, and thus are hot issues attended to by linguists. Lexicalization indicates the linguistic fact that a non-lexical element evolves into a lexical element or an element with less lexical features evolves into one with more lexical features [1], resulting in lexicalized items from compounding, derivation, acronym, syntactic structures, etc. [2]. There are various factors motivating the process of lexicalization, such as social communicative environments, phonetic changes, syntactic contexts, influences of borrowed expressions, and so on, which have already drawn the attention from many researchers. But received wisdom has rarely touched upon the cognitive motivations for lexicalization except that some researcher have realized that "mental phenomena" are involved in the process of lexicalization [1], without going into it deeply. I claim in this present article that the boundary movement phenomenon manifested in the process, called "boundary assignment" in this paper, is actually a human cognitive ability driving language evolution, and thus a motivation for lexicalization. I hereby take lexicalization phenomenon in the Chinese language as an example to illustrate the fact that boundary assignment is an important cognitive motivating force for lexicalization.

\section{Studies on Motivating Factors for Lexicalization}

\subsection{Semantic Relation Changes as the Motivation of Lexicalization}

This theory claims that it is the semantic relation change in contexts that motivates lexicalization [3]. For example, ran'er(so but), which first appeared in Warring States literatures and has turned into one word in modern Chinese meaning "however", were originally two separate words with different meanings and serving different functions in discourse. Liu [3] summarizes ran'er's grammatical behaviors into four models: A. "S, ran er VP1zhe (particle) + 
VP2ye(particle)"; B. "S, ran-er Vpye(particle)"; C. "S1, ran-er $\mathrm{S} 2$ "; D. "S1, Ran'er S2". Originally (as in A), ran functioned as a reiteration of $\mathrm{S}_{1}$ to emphasize and provide a condition to introduce adversative er (but). Later, as in B, along with the changes of ran's meaning and grammatical function, $\mathrm{S} 1$ is no longer the condition for er(but), and ran served only as a kind of acknowledgement of the proposition of S1. In this stage ran $e r$ is approximately equal to modern Chinese "although it is so, but..." in meaning. In $\mathrm{C}, \mathrm{S} 2$ with the "S VP" structure appeared, and thus er was isolated from $\mathrm{S}_{2}$ such that $\mathrm{er}$ was forced to move leftward to form a prosodic unit with $\mathrm{ran}$. This motivates ran and er to turn into a word. To the stage of D, ran and er gradually lost their independent sematic functions completely and is lexicalized as a disyllabic word "ran'er", meaning "but" or "however". This process is seen by Liu [3] as the motivation for lexicalization.

Dong [1] also claims that when the syntactic function of a content word changes, its composition with other words will lose productivity and be lexicalized. One example is the loss of the attributive function of verbs in the pre-Qin Chinese resulting in lexicalization, e.g. jian chen, literally "criticize minister"was originally a"V(as attributive) $+\mathrm{N}$ " structure, meaning "minister in court who likes to criticize"and later became a dicyllabic word meaning "minister whose role in court is to put forward criticizing ideas", as the result of the loss of the verb jian's attributive function. Other examples include the loss of the adverbial function of nouns leading to lexicalization, e.g. wa jie, literally "tile break", a"N (as adverbial) $+V$ "structure in ancient Chinese with the meaning of "break as tiles do", gradually became lexicalized into a disyllabic word, meaning "collapse".

\subsection{Syntactic Environment Changes as the Motivation of Lexicalization}

This theory claims that it is the syntactic change in contexts that motivates lexicalization. For example, some functional words' disappearance in syntactic structures in history caused the juxtaposition of two content words, which provided a syntactic environment for juxtaposed monosyllabic words to blend into a disyllabic word. The first case is the loss of the conjunction er as in xian quan ji er hou qiu ming, literally "first preserve oneself and later seek reputation". The loss of the function of the conjunction er in the sentence caused the reader to construe er (and) and hou (later) as one word. Therefore, er and hou became a disyllabic adverb erhou meaning "then". Another case is the loss of the preposition $y u$ before a noun as in de shi bu guan yu xin, literally "gain loss not care in heart", meaning "do not care about gains and losses". The loss of $y u$ caused the juxtaposition of guan(care) and $x i n$ (heart) and finally the two word originally pertaining to two different levels in syntax were lexicalized into a disyllabic word guanxin, meaning "concern" [4].

Another kind of syntactic environment change occurs in the change of the word order in sentences. In the pre-Qin Chinese, a pronoun as an object should be put before the verb or the preposition in some situations, especially the pronoun he (what) as the object of a preposition in an interrogative sentence. For example, he yi zeng zhi? qiong gui yu pei are lines from The Book of Songs, literally "what with give him? jewel jasper jade pendant", meaning "What can I give him as presents? Precious jewels and jade pendants". From the Han Dynasty on, he gradually moved to the position following the preposition and the Obj-Pre order for he disappeared, but the form he yi (what with) was left intact and conventionalized into a disyllabic word meaning of why or how. Also in the history of the Chinese language, there was a process in which prepositional phrases moved from the position following a verb to that before it, with some still left in the original position as a result of frequent use. This led to the phenomenon of post verb preposition blending with the verb construed as s disyllabic word, thus lexicalized. For example, in an ancient Chinese sentence gu ye yuan yu ma qian, literally "ancient also origin in Maqian, meaning "originated from Maqian (i.e. Sima Qian) in the ancient times", the underlined $y u$ is a preposition approximately meaning "in" or "from" with Maqian as its object. Later on, because most PP went to the pre-verb position, language users took this remaining preposition $y u$ as a morpheme within the verb. Therefore, a new disyllabic verb yuanyu came into being, meaning "originate from" or "come from"[1].

\subsection{Disyllabification Trend as the Motivation of Lexicalization}

In the pre-Qin Chinese most words were monosyllabic. A trend of disyllabification began to flourish 2000 years ago [5; 6] and became prevalent in the medieval Chinese period. Pushed by this trend, two monosyllabic words juxtaposed began to blend into a compound word, e.g. dong zhi, "literally winter arrive", and zhu xi, literally "hold chair", turned into dongzhi and zhuxi, meaning "winter solstice" and "chairman" respectively [6]. Shi [6] claims that the disyllabification trend pushed the formation of the Chinese resultative structure - a construction-like disyllabic word -- by the blending of the monosyllabic verb and the resultative morpheme (originally also a verb or an adjective). A typical example is the Chinese word dapo (break). Originally in the ancient Chinese dapo were actually two monosyllabic transitive verbs $d a$ (hit) and po (break) each with its own object and the two verbs were separated by the object of the first verb $d a$. And according to the grammatical conventions of the day, if the objects of two verbs were the same it was allowed to take the syntactic position after the second verb, i.e., " $\left[\mathrm{V}_{1} \mathrm{~V}_{2}\right] \mathrm{O}$ "pattern was grammatical. As soon as " $\left[\mathrm{V}_{1} \mathrm{~V}_{2}\right]$ " appeared in use, the condition for disyllabification was satisfied and under the push of the trend the two verbs blended into a disyllabic resultative verb dapo (break). Whenever the disyllabification trend captures a phrase which is disyllabic, the syntactic relation between the two monosyllabic elements will be obscured and the two elements will be easily blended into a word [4].

\subsection{Reanalysis as the Motivation of Lexicalization}

Reanalysis was taken by many researchers as the 
mechanism of grammaticalization. Since lexicalization and grammaticalization often overlap in not a few aspects [7], it is also treated as a motivation of lexicalization. In the above sections, almost all the examples taken for the analysis of diachronic lexicalization process involve reanalysis. Not only diachronically but also synchronically lexicalization can not happen without reanalysis. For example, in modern Chinese, kejian (can see) is originally a phrase, as in bu shi ke jian niu zai shan po shang man bu, literally "not time can see cow on hill slope lazily walk", meaning "we can see now and then cows are rambling on the mountain slope", in which ke(can) is an auxiliary verb and jian(see) a verb. But in the sentence ke jian Jack shuiping gao yi xie, literally "can see Jack skill high a little", meaning "It is easily seen that Jack is more skillful", in which there is no longer clearly visible images. In the sentence ke jian, zhege fang'an bu hao, literally "can see this plan not good", meaning "as it shows, this plan is not good", in which kejian is separated from the sentence proper and a comma is used in between. In this way the two words $k e$ and jian are no longer an Auxi+V structure, but reanalyzed and lexicalized as a conjunction [8].

The arguments reviewed above are reasonable in different aspects, but I argue that if language is described as a symbolic assembly, the motivations they claimed are only the superficial manifestations at the phonological pole in the conversion from syntactical elements to lexical elements. Seen from the surface it is indeed the semantic relation change, the syntactic context change or the disyllabification trend that motivates syntactic elements to merge into morphological elements, but as cognitive linguists we know the fact that language change is not a phenomenon pertaining to language itself but to the ways we use language. In order to use a definite number of linguistic expressions to express indefinite experiences of the world, humans have to break some linguistic conventions in some way or other to satisfy their needs. That is the basic cause for language change [9]. According to cognitive linguistics' view, linguistic ability is an inseparable part of general cognitive abilities [10], so human cognitive insights into the world is the fundamental motivation for linguistic activities, therefore, a fundamental motivation for language change.

As I have shown in the above sections, lexicalization involves structural relation change which is in fact an activity of structural boundary rearrangement or reanalysis, which in turn is a basic conceptualizing ability of boundary assignment gained by human beings in the process of their contact with the world. Although some researchers have realized that reanalysis is a kind of "cognitive activity" [11] or a "mental power" [12], nevertheless they still treat it as a structural phenomenon rather than a conceptualizing ability. We can see this from Ma Qinghua's statement [12] that reanalysis is a mental power denoted by $(\mathrm{AB}) \mathrm{C} \rightarrow \mathrm{A}(\mathrm{BC})$, e.g. from shan $y u X$ (good at $\mathrm{X}$ ) to shanyu $X$ (skillful in $\mathrm{X}$ ) and from gan $y u X$ (brave at $\mathrm{X}$ ) to ganyu $X($ dare do $\mathrm{X}$ ). Deficiencies shown in the former researches leave us some space to explore into the cognitive motivation of lexicalization.

\section{Boundary Assignment Is the Basic Motivation of Linguistic Structural Organizing Activities}

When human beings encounter the world they tend to recognize the entities in it as structural wholes. This tendency to see things as integral wholes is nothing other than the result of Gestalt Laws, which dominate human perception and cognition. Therefore, everything in our eyes is a structure-boundary unity. Our recognition of linguistic structures also observes these laws. We can not discern a linguistic structure before we decide where its boundaries are $[13,14]$. Without the ability to establish the boundaries we are not able to decide what a structure is like. We call this structural boundary establishing ability "boundary assignment". In the process of construing a linguistic structure, syntactic or semantic, we have to assign boundaries to it, or we are not able to know its relation to other structures and the larger whole. Different boundary assignment will lead to different structures and different understandings. For example,

(1) I heard [the man in the next house].

(2) I [heard the man in the next house].

(3) [I heard the man in the next house].

In the above examples the squares indicate the boundaries assigned to the component structures of the sentence. In(1), in the next house is analyzed through boundary assigning as a modifier of NP, i.e., this man, not a man outside the house, was heard. In (2) in the next house is an adverbial modifying VP, i.e., I heard the man's voice coming from the house, with the meaning "he ran away when I reached the house". In (3), in the next house is an adverbial of the whole sentence, i.e. it is when I was in the next house I heard the man, with the meaning "I couldn't hear him any more when I left that house.

The phenomenon is often seen in modern Chinese whose words are not separated by blank spaces as in English and can be of one syllable, two syllables or even more. Boundary assigning activity is always required in construing Chinese expressions though we are usually not conscious of it except in some special cases. For example,

$\begin{array}{cccccc}\text { (4) henan } & \text { nongmin } & \text { daxue } & \text { juban } & \text { chaye peixun } & \text { ban } \\ \text { Henan } & \text { farmer } & \text { university hold } & \text { tea } & \text { training } & \text { class }\end{array}$

a. Henan Farmer University organized a training course of tea techniques.

b. Famers from Henan organized training courses of tea techniques at universities.

When we boundarize henan nongmin daxue (Henan Farmers University) as a unit, it is the name of a university and the sentence means a. If we put "henan nongmin" (farmers from Henan Province) together as a unit in boundary assigning operation the sentence is read as $b$.

Such examples are often seen in daily life. In order to remember our bank card password more easily we usually invest it with meaning, such as the date of birth 85-07-30. If someone mentions it with a different structure such as $850-731$, we would not be able to recognize it immediately without 
some cognitive efforts. The difficulty in recognition is caused by the discrepancy in boundary assignment. It is also true of mobile phone numbers. In China mobile phone numbers have 11 digits. Most people remember it in a 3-4-4 structure, with the first part as the network identification number, the second part the area code and the last part subscriber number. Some people like to remember if in different ways like 3-3-5. If someone says your number in a different way from yours, you would likely be at a loss because of the different boundary assignment.

Boundary assigning ability is a fundamental ability to discern the world and the relations between things in the world, and thus an indispensable ability in the production and understanding of linguistic expressions. Lexicalization always involves rearrangement of syntactic structures, therefore, boundary assignment is especially vital in this process. Today's morphology is yesterday's syntax [15]. Lexicalization process is a process in which a syntactic structure evolves into a lexical item through the merging of two or more separable structural elements into an inseparable single element. Boundary loss, boundary shift and boundary creation must occur in this process [16]. In fact, not only lexicalization and grammaticalization but also all linguistic structural changes are motivated by boundary assigning operations. Cognitive psychology finds that understanding the information conveyed by syntactic structures is actually an information processing in human brain, in which language users tend to group elements into integral units when possible [17]. This is called "chunking". Different "chunkings" lead to reanalysis, which is in fact a different way of boundary assignment. Semantic construction is conceptualization [17]. Boundary assigning occurs at conceptual level and symbolized by linguistic forms. Thus boundary assignment underlies the organization of all linguistic structures and naturally an important motivation for lexicalization.

\section{Boundary Assignment's Manifestation in the Process of Lexicalization}

Lexicalization is a form of language change from discourse, syntax or phrase structures to the direction of words, thus a lingistic innovation. There are usually three causes for language users to use an innovative form. The first is that language users deliberately break the prevailing structural conventions by assigning boundaries wrongly to some structures for some special communication purposes, e.g. for economy or humor. The second is that certain language users commit an undeliberate grammatical mistake with improper boundary assignment. The third is that the language receiver wrongly understands the producer's structural arrangement by assigning different boundaries to some structures from the producer's purpose. In the first two cases if the receiver come to an agreement on the intended meaning with the producer in communication, and the communicators further find that the unconventional structure has some merits, e.g. conciseness or novelty, they will continue to use the novel form so that it is spread in the community. Through frequent use this new form may entrench itself and becomes a new conventional unit [18]. Then innovation happens. In the third case, the wrong interpretation of a conventional structure may happen to be taken by communicators as an exotica and appreciated for its newness. Then it may be spread in a community and even entrenched as a unit in the inventory.

Whether a novel form can be accepted, spread or entrenched depends on whether it conforms to human cognitive tendencies, e.g., the Gestalt Laws. That is why Lexicalization from syntactic elements to lexical items must obey the law of proximity, i.e., the two syntactic elements must be juxtaposed, or else language users' ability to establish a integral whole will be damaged to make it difficult to recognize the novel structure as wholesome.

In this chapter, we take some cases to illustrate the manifestation of boundary assignment in the process of lexicalization. It can be seen from the following illustration that so-called motivations reviewed in Chapter 2 are actually the effect of boundary assignment. That is, these "motivations" are motivated by boundary assigning operations on linguistic structures.

\subsection{Lexicalization of "Rongyi": Boundary Assignment Motivates Semantic Relation Change}

In modern Chinese the word rongyi is an adjective or adverb made up of two unanalyzable morphemes, meaning "not difficult", "likely", "easy" or "easily", but in ancient Chinese the two morphemes were actually two separate monosyllabic words, though they were juxtaposed in syntax. Rong means "allow" or "permit", and $y i$ means "disdain", "negligence" or "ignorance".

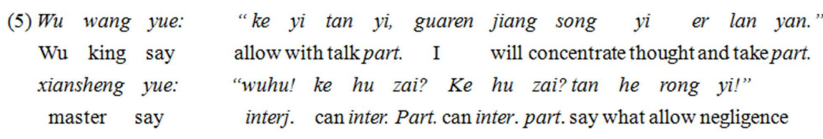

King Wu said, "You can talk about it and I will concentrate my self and listen carefully". The master said, "Alas! Can I? Can I? How can I be disdainful!" --from Hanshu, the East Han Dynasty

(notations: part. $=$ particle; interj. $=$ interjection; inter $=$ interrogative. The same bellow)

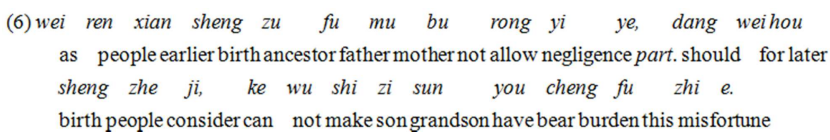

As parents and grandparents we should not be reckless. We should take our offspring into consideration. Only in this way can we save our descendants from misfortune. --from Shilun, the East Han Dynasty.

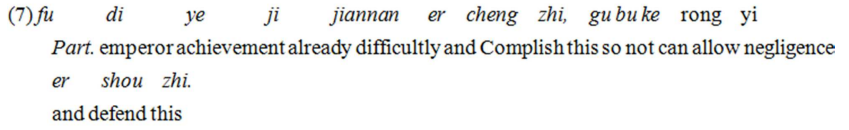

Now that the Emperor's accomplishments has been achieved with difficulties, we should defend it without any 
negligence. --from Jiutangshu, the Tang Dynasty.

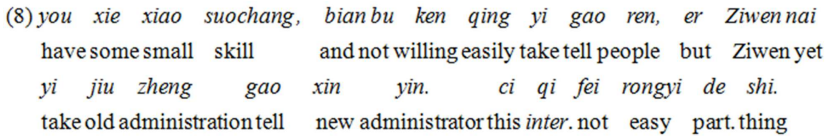

When people have some skills they are not willing to let others know. But Ziwen tells the new administrator all his administrative policies, which is not an easy thing to do. -from Zhuziyulei, the Song Dynasty.

(9) ren sheng zai shi he rongyi, yan zhuo xin hun xin sheng si.

People live in world inter. easy eyecloudy heart duskybelievelife death

It is not an easy thing to live in the world. Now with cloudy eyes and ignorant heart I no longer care about life or death. -from the Collection of Yuefu Poems, the Song Dynasty.

(10)xian zhu dao: "laonian ren rongyi hunjue, wei bi shi da." countyleader say aged people easily faint not necessary is beat

The county magistrate said: "The aged people easily become shocked, so it is not necessary to beat him." - from Selected Stories of the Yuan Dynasty, the Yuan Dynasty.

\section{(11) ni shi qiong ren zen dao kan de zheyang rongyi? you are poor people how should see part. so easy}

You are a poor man but why should you take it so easy? from Jinguqiguan, the Ming Dynasty.

Rong yi first appeared in the Han Dynasty, which were originally a $\mathrm{V}+\mathrm{O}$ structure with the verb Rong meaning "allow" or "permit", and the noun $y i$ meaning "negligence" or "ignorance". Before lexicalized this $\mathrm{V}+\mathrm{O}$ structure meant "allow negligence"[19]. As shown in (5), it conveys the meaning "(to talk with the king does not) allow negligence" or "(how can I) allow (myself) to make nonsense". In (6), bu rong yi ( literally not allow negligence) has the similar meaning, i.e., "(as parents we should) be careful ( about our moral behaviors)". Because the negative adverb is positioned before rong yi the reader will likely reads it as "(it is not) easy (to cultivate posterities )". That is probably the environment for the meaning of "easy" or "not difficult" to germinate. In (7) drawn from the Tang literature, we can see that rong yi still means "allow negligence" and language users still tend to construe it as a $\mathrm{V}+\mathrm{O}$ structure at the time. Then in (8) drawn from the Song, we had better read rong $y i$ as a disyllabic adjective than a $\mathrm{V}+\mathrm{O}$ structure, meaning "easy". In (9) and (10), it becomes difficult for readers to analyze rongyi into two separate words. It is used even as an adverb meaning "easily" in (10), which is drawn from the Yuan Dynasty literature. Rongyi completed the process of lexicalization in the Yuan and Ming Dynasties.

From the above analyses we can clearly see the roles of boundary assignment in the process of the $\mathrm{V}+\mathrm{O}$ rong yi's evolution into a disyllabic word. It is the boundary assigning ability at the conceptual level that causes two words to merge into one. Because the word rong and $y i$ are juxtaposed in the text and can be interpreted as "easy" in meaning, language users tend to eliminate the boundary between the original V and $\mathrm{O}$ and reset a new boundary to the structure such that the two words become one. Still because the newly created word conforms to disyllabification tendency prevailing and more expressive, it is accepted by the users and spread in linguistic communities and entrenched itself in the linguistic unit inventory as a new schema categorizing new comers. In this process the semantic relation between rong and $y i$ changed because the noun feature of $y i$ and the verb feature of rong lost. Seen from this perspective, semantic relation change in history, regarded as the motivation of lexicalization by some researchers such as shown in Section 2.1, is a result of the conceptual boundary assignment.

According to cognitive grammar, which recognizes the mutual influence between cognition and language and heavily emphasizes the conceptualization [20], an utterance activates a grammatical schema to establish a categorizing relation to justify its status as a grammatical expression. The relation between the categorizing schema and the categorized expression can be of elaboration (a prototypical instance of the schema) or of extension (peripheral instance). For example, in (5) the schema activated is [VO], but in (6), because of the negative "not" appears language users are likely hesitating to decide whether he should choose $[$ not $+\mathrm{V}+\mathrm{O}]$ schema or that of $[\mathrm{Adv}+\mathrm{Adj}]$ under the pressure of convention and the new disyllabification trend, although it is possible that the speaker or the writer still use it as a "V+O" structure. Up to (10) and (11), the process of lexicalization has been completed and both the meaning of "easy" or "easily" and the form as a disyllabic word have entrenched themselves in the inventory, and language users will not hesitate to construe it as a word rather than a VO structure.

Of course, because lexicalization is a long time process we can not precisely know who in what situation first uses or construes rongyi as a word. However, we can still infer by abduction according to human cognitive features and abilities that different boundary assignment first happens because language users deliberately break the linguistic convention for some special communicative purposes or commit mistakes unintentionally, or because language receivers ambiguously understand the original boundary assignment by the speakers or authors. Only when the new structures effected by different boundary assignment are found advantageous in some aspects by language users can they become prevalent in use and entrench themselves as new units.

\subsection{Lexicalization of "Shezhong": Boundary Assignment Motivates Syntactic Environment Change}

In the ancient Chinese rong and $y i$ discussed above are always adjacent in syntax, so they are blended at conceptual level to be understood a s a disyllabic word under the control of Gestalt Laws. Boundary reassigning metal operation in this process can be felt intuitively. But the lexicalization process of she and zhong (shoot and hit) is far more complicated for they were originally two verbs each with their objects and separated in syntax in the ancient Chinese in forms like "she $O$ zhong O"(VO+VO), "she er zhong O" (V conj. part. +VO) or 
"she O zhong" (VO+Vi).

We abstract from CCL database of the ancient Chinese 957 items involving all forms of the collocation of she zhong suitable for this study, and analyze the data manually as illustrated in the following table.

Table 1. Ratio of she zhong against she $(O)$ zhong $(O)$ in historical readings.

\begin{tabular}{llll}
\hline Dynasties & "she zhong" & "she O(er) zhong(O)" & "she zhong"\% \\
\hline Spring and Autumn & 0 & 5 & 0 \\
Warring States & 3 & 43 & 6.5 \\
Han, Tang and Six Dynasties & 19 & 27 & 41 \\
Song & 99 & 163 & 37.7 \\
Yuan and Ming & 114 & 7 & 94 \\
Qing & 155 & 36 & 81 \\
Minguo & 205 & 81 & 71 \\
\hline
\end{tabular}

The verbs she and zhong first appeared in the Spring and Autumn period. The cases of the juxtaposition of the two verbs increased quickly since the Song Dynasty, and became prevalent to the Yuan and Ming Dynasties. It is in the Yuan and Ming Dynasties that she and zhong were lexicalized and entrenched as a resultative verb. I select some examples from the data I have analyzed and display them in temporal order so that the evolutionary process can be easily seen.

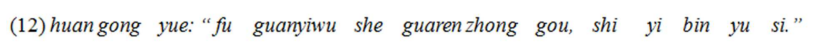

Duke Huan said: "GUanyiwu shot at me and hit my belt hook and I was almost dead because of this." -from Guoyu, the Spring and Autumn period

(13) ranshu she chenwuzi, zhong shou, shi gong er ma. RanShushootChen Wuzi hit hand lose bow and curse

Ran Shu shot at Chen Wuzi and hit his hand. His bow dropped on the floor and he cursed. -from Zuozhuan, the Spring and Autumn period

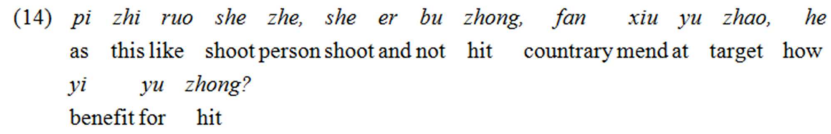

Just as in archery when you fail in hitting the target, you try to mend the target. This is no good for you to hit it. ---from Lushichunqiu, the Warring States

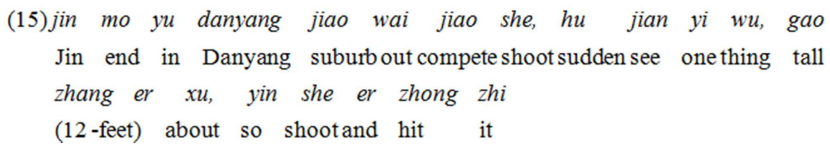

In the end period of Kingdom Jin, (Liu Juanzi) took part in the contest of shooting in the suburb of Danyang City. He suddenly saw something like a monster about 3 meters tall. So he shot at it and hit it. -from Liu Juanzi's Prescription Left by $a$ Ghost, the Six Dynasties

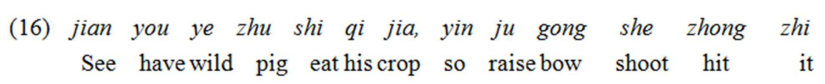

(He) saw a wild boar eating his crops, so (he) raise the bow to shoot and kill it. -from Taipingguangji, the North Song Dynasty
(17) $x u$ shi she zhong hong xin zhi zhong, fang shi must be shoot hit red heartpart.middle, then be

Goals can only be scored only the red bull's eye in the middle is hit. -from Zhuziyulei, the North Song Dynasty

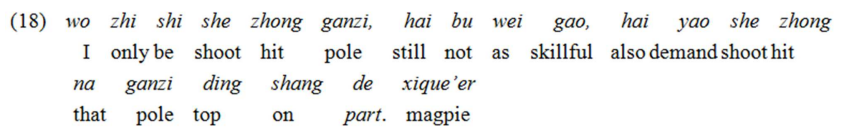

I only shot the pole. It is far from brilliant. I can shoot the magpie on the top of the pole. -from The Eunuch Sanbao in the Western World, the Ming Dynasty

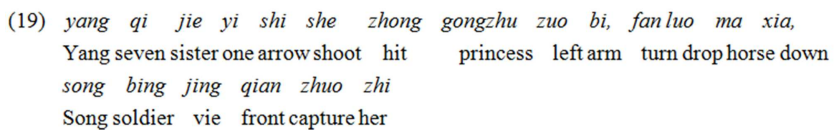

Seventh Sister Yang shot the princess' left arm and the princess dropped from the horse down to the ground. The soldiers of the Song struggled with one another to capture her. -from The Generals from the Yang Family, the Qing Dynasty

When first appearing in literatures, she (shoot) and zhong (hit) were two verbs each with its own object, as in (12)-(14), so they were detached. She was also used as an intransitive verb with er (and) between it and zhong, as shown in (15). A few cases of the juxtaposition of the two words can be seen in the Warring States' literature. That was only because both are used intransitively without punctuations inserted in between in the ancient Chines. For example, liezi chang she zhong yi, qing zhi yu guanyuzi, literally "Liezi once shoot hit part., consult from Guan Yuzi", meaning "Liezi once shot and hit the target and he went to seek advice from Guan Yuzi".

According to the statistical data shown in the table, the proportion of juxtaposed she and zhong had increased to $38 \%$ in the Song Dynasty. The suspected resultative verb form had appeared as shown in (17), with most of them still analyzable as serial verbs as seen in (16). Up to the Yuan and Ming dynasties about $90 \%$ of she and zhong became juxtaposed and the lexicalization process of shezhong was completed.

If syntactic juxtaposition is the necessary condition for lexicalization, does it mean that boundary assigning mental activity only occurs after syntactically separated elements like she and zhong come together in juxtaposition? Certainly not. Now that boundary assigning motivates all the linguistic organizing activities including syntactic relation change, it is 
actually boundary assigning force that pushes the syntactically separated elements together. As Langacker [10] claims, a linguistic unit is not limited to a specific position in a syntactic tree as described by formal linguists but they can occupy more than one positions as is seen in the following figure. In the figure the tree diagram indicates traditional linguistic units, the boxes indicate the positions linguistic units in symbolic assembly possibly occupy.

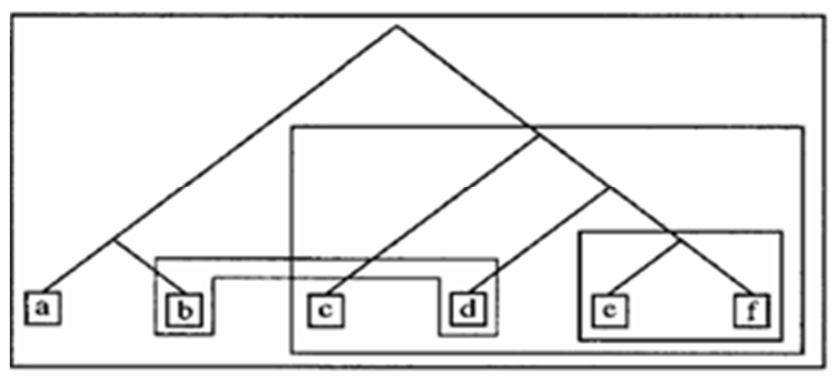

Figure 1. Word exhibiting internal syntactic structure [from 10].

According to Langacker's theory we can describe the process of the separated she and zhong's syntactical position change as follows: since the relation represented by the actions she and zhong is that of cause and effect, which are closely related in conception, language users, dominated by Gestalt Laws, naturally construe them as a conceptual whole. This construal edges out the conjunction er (and) between intransitive she and transitive zhong (drop of er was allowed by syntactic convention at the time), and presses zhong to move to the position following she. Since she and zhong become juxtaposed as a result of the first step of boundary assigning, language users continue to reassigning boundaries to shezhong, as they do in the lexicalization process of rongyi, and complete the process of conceptualizing it as a resultative verb as in (18) and (19). We can see from the lexicalization process of shezhong that boundary assignment also motivates syntactic environment changes.

The reason why the lexicalization of shezhong was not completed until the Yuan and Ming Dynasties is that before the Yuan and Ming the cases of juxtaposition of she and zhong did not prevail in usage events because only the written language was widely spread. Up to the Yuan and Ming because the story-tellers' scripts appeared and the oral language had more chances to be written down for record and came into literatures, the frequency of shezhong used as a resultative verb rapidly increased, which helped the effect of boundary assignment impact on the lexicalized use of shezhong.

\subsection{Synchronic Lexicalization: Boundary Assignment Motivates Synchronic Structural Changes}

Lexicalization does not require diachronic studies as its necessary condition because several different forms from different historical periods can be active simultaneously in the modern linguistic system [21]. A typical example is the evolution of $\mathrm{V}+\mathrm{O}$ structure to a disyllabic verb. Since 1970s a structure of $\mathrm{VO}+\mathrm{O}$ appeared in Chinese, which was not allowed by the Chinese grammatical convention except in ditransitive verbs [22], such as liang xiang yinmu (show oneself on the screen) and cheng ba wulin (seek hegemony in martial arts circles). Originally liang (show) and cheng (claim) were verbs taking their noun objects xiang (pose) and $b a$ (lord) respectively. So liang xiang and cheng $b a$ were actually $\mathrm{V}+\mathrm{O}$ structures and could not be followed by another object. Probably because they often appeared in some special discourse contexts like newspaper deadlines, language users, for some special needs, say, that of conciseness, used them as a disyllabic verb and moved the location words originally as the object of a preposition to the position ditrectly following $\mathrm{V}+\mathrm{O}$ structure. Then the location word was taken by readers as the "object" and the $\mathrm{V}+\mathrm{O}$ structure as a disyllabic word. This process is of course also motivated by human tendency of boundary assignment in the construal of linguistic structures. Because the newborn novel structure is concise and expressive the reader accept and spread them in expressions, and their lexicalization process is thus completed. The operation of boundary assignment can be easily seen in this process.

Another example of synchronic lexicalization is ye (also) hao (good) in modern Chinese. As the two words' literal meaning shows, they were originally an Adv+Adj structure, meaning "also good". For example, ta de wenzhang hao, weiren ye hao, literally "his writing good, moral quality also good", is a coordinate sentence in the form of "A is good and $\mathrm{B}$ is also good", in which ye is an adverb modifying hao. In some communicative environment the coordinate item A can be omitted, e.g, gaosu ta ye hao (literally: tell him also good; meaning: we may as well tell him about it), in which ye hao is still the predicate. Ye hao can also appear in complex sentences, e.g., suiran bu yiding chenggong, zhengqu yi xia ye hao(literally: although not necessary succeed, try a bit also good; meaning: altough we may not succeed we may as well have a try ), in which ye hao is still a predicate indicating subjective evaluation. But in deng ta yi hui ye hao, miande ta baoyuan (literally: wait him a while ye hao, lest he complain; meaning: We may as well wait for him a while lest he should complain), ye hao introduces a subordinate clause and thus loses some of it content word meaning and its predicative function [23]. In ni shuo ye hao bu shuo ye hao, shishi jiushi shishi(literally: you say also good, not say also good, fact is fact; meaning: no matter what your opinion is, it is a fact), ye hao completely loses is predicative function and lexicalized into a conjunctive particle word yehao designating listing something. We can clearly see from the analyses of these examples that the process of the lexicalization of ye hao from an $\mathrm{Adv}+\mathrm{Adj}$ structure composed of two words into a conjunctive particle word yehao is motivated by the mental operation of boundary reassigning activities.

\section{Conclusion}

Language is used by human beings and language study needs to be usage-based [5], so language evolution is closely related to language users' mental activities. To express themselves language users have to organize concepts they 
obtain from the world experiences in structures so that they can establish the relations between the world entities. Boundary assignment is a fundamental ability for humans to organize conceptual structures directed by Gestalt Laws. Thus it is always a motivating force for linguistic structure organizations. Lexicalization, which is a kind of linguistic structural change, is naturally motivated by it. The lexicalization process generally develops in the following way: a conventional syntactic is broken by a certain language user to create a novel expression for some communicative purpose, involving a certain reassignment of linguistic structural boundaries. As a result a new structure appeared. This newly created structure is understandable and accepted by interlocutors as a useful structure with some communicative advantages such as being concise, economic or more powerful in expressing something. The new structure can be a syntactic structure new from the former one or directly taken as a new word if it looks like a word. Then it is spread in communication and lexicalization occurs.

The process of lexicalization is complex, but seen from the cognitive perspective boundary assignment is a fundamental force to motivate this linguistic phenomenon. The phenomena of analog, reanalysis and chunking found in previous studies are only manifestations of boundary assigning tendency in the organization of linguistic structures at conceptual level. Therefore boundary assignment is a main cognitive force to push forward changes of linguistic structures including lexicalization.

\section{References}

[1] Dong, X. F. The syntactic evolution of the Chinese language and lexicalization [J]. Chinese Language. 2009(5):399-409.

[2] Brinton, L. \& E. Traugott. Lexicalization and Language Change [M]. Cambridge: Cambridge University Press. 2005.

[3] Liu, L. The process of lexicalization of ran'er and its motivation [J]. Journal of Beijing Normal University (Social Science Edition). 2008(5):49-55.

[4] Dong, X. F. Lexicalization: the derivation and development of Chinese disyllabic word [M]. Chengdu: Sichuan Nationalities Publishing House. 2013.

[5] Guo, X. L. The development of word-building in the Pre-Qin Chinese [A]. In Guo, X. L. (ed.) A Collection on the History of the Chinese Language [C]. Beijing: Commercial Press. 1997.

[6] Shi, Y. Z. The Establishment of Modern Chinese Grammar: The Formation of Resultative Construction in the History of Chinese and its Effects [M]. Philadelphia \& Amsterdam: John Benjamins Publishing Company. 2003.
[7] Liu, H. N. Lexicalization of napa [J]. Nankai Linguistic Journal 2010(1): 142-150.

[8] Wang, M. H. The manifestation of lexicalized particles and non-words at synchronic level [J]. Journal of Ankang College. 2011(5):38-41.

[9] Croft, W. Explaining Language Change: An Evolutionary Approach [M]. London: Longman. 2000.

[10] Langacker, R. Cognitive Grammar - A Basic Introduction [M] New York: Oxford University Press. 2008.

[11] Wang, C. L. Two examples of lexicalization-the relation between lexicalization and grammaticalization [J]. Contemporary Linguistics. 2005(3):225-236.

[12] Ma, Q. H. The motivation of lexicalization [J]. Chinese Lnguage Learning. 2003(2):15-20.

[13] Liu, C. D. Boundary movement: a motivation for linguistic innovation [J]. Foreign Languages Research. 2012(1):30-34.

[14] Liu, C. D. The establishment of structure-boundary unity: a cognitive basis for the construction of linguistic expressions [J]. Foreign Language Teaching and Research. 2008(3): 204-210.

[15] Givón, T. Historical syntax and synchronic morphology: an archaeologist's field trip [A]. Proceedings of the 7th regional meeting of the Chicago linguistics society [C]. Chicago: linguistics society, 1971: 394-415.

[16] Langacker, R. Syntactic reanalysis [A]. In Li, C. (ed.) Mechanisms of Syntactic Change [C]. Austin: University of Texas Press.1977:57-139.

[17] Evans, V. \& M. Green. Cognitive Linguistics: An Introduction [M]. Edinburgh: Edinburgh University Press. 2006.

[18] Keller, R. On Language Change: The Invisible Hand in Language [M]. London: Routledge. 1994.

[19] Cao, R. The lexicalization of rongyi and rong's meaning of "permission" [J]. Chinese Language Learning. 2007 (1):37-40.

[20] Bielak, J. Applying Cognitive Grammar in the Foreign Language Classroom [M]. Springer-Verlag Berlin Heidelberg. 2013.

[21] Li, W. S. The three haiyou in modern Chinese-lexicalization in synchronic materials $[\mathrm{J}]$. Chinese Language Learning. 2008 (5):55-61.

[22] Xing, G. W. A seemingly prevalent suspicious syntactic structure--VO+O [J]. Language Planning. 1997 (4): 21-23.

[23] Pan, G. Y. \& H. Y. Qi. Lexicalization of yehao. Chinese Lnguage Learning. 2009(5): 20-27.

[24] Dancygier, B. The Cambridge Handbook of Cognitive Linguistics [C]. Cambridge: Cambridge University Press. 2017. 